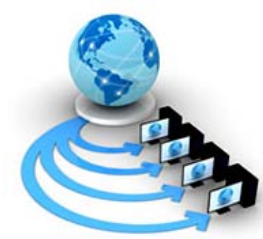

Volume 10, No. 4, July - August 2019

\title{
STRUCTURAL DESIGN AND RESEARCH OF FORMING MODEL FOR THIN- WALLED PARTS
}

\author{
Yanan QIN \\ Binzhou University \\ Binzhou, China
}

\begin{abstract}
In view of the fact that the fibre composites belong to thermosetting materials, the moulding process is adopted. Carbon fiber composite blank was preheated and softened, and then the blank was put into the die cavity to close the die. Carbon fiber composite products were obtained by heating and solidifying the mould, cooling and demoulding. In the design of the die, the integral die and the combined block punch are used. When the upside-down phenomenon exists in the assembly of the die, it is easy to open the die. The processing technology and assembly requirements of the die are put forward.
\end{abstract}

Keywords: moulding; thin-walled part; form; process; structure design

\section{INTRODUCTION}

The forming process of thin-walled components is not to change the thickness of components, but to change the surface shape of components [1]. In addition, the forming process also requires high temperature curing. According to these forming requirements and the fluidity of composite products, the moldings process is selected. Molding is also called pressing. polyacrylonitrile-based carbon fiber composite has good forming effect and meets the requirements of light weight and strong strength for products. According to the physical characteristics of the material, the blank must be preheated before loading [2]. Generally, the blank is heated in the oven to soften the composite material and increase the fluidity of the material to facilitate the loading of the mould. The preheating process also dries the composites, removes moisture from the interior of the materials and reduces the forming pressure required for pressing. Then put in the mould to fix the structure, and finally apply pressure and temperature to solidify [3]. The advantages of this forming method are simple process, easy operation, and no waste of raw materials, good mechanical properties and appearance quality, and no secondary processing after forming. Therefore, in terms of production efficiency, it has obvious advantages over other forming methods. For thinwalled parts, the uniformity of forming pressure should be guaranteed by the mould in the forming process, so as to ensure the design accuracy of the products and meet the inherent quality of the products. The basic idea of mould design is to divide the core of the mould according to the change of the surface structure and curvature of the product, adopt the combination block and variable slope core structure, and assemble each combination block with high precision in the process of mould assembly, so as to ensure that the positive pressure of the product is the same at all points, so as to meet the requirement of forming thickness error of $0.02 \mathrm{~mm}$.

Because the curvature of carbon fiber products varies greatly, and the hardness of the products after molding is larger, the surface accuracy of the products is higher. Considering all factors, the product must fall off smoothly when designing the remolding mechanism of the mould. Because the ideal opening state is to keep the molded product in the mould, the remolding mechanism can be designed on the integral mould. Because of the high forming pressure, the reverse taper is adopted for the ejection ejector rod, and the tighter the pressure is, the better the overflow is avoided.

\section{FORMING PROCESS CHARACTERISTICS OF THIN- WALLED PARTS}

\section{A. Geometric characteristics}

The products studied in this paper are reinforcing sheets on sports equipment, as shown in Fig.1. It requires light weight, high strength and good impact resistance. Carbon fiber composite meets these requirements. The carbon fiber composite material used in this product belongs to thermosetting material. It has good plasticity, good forming process performance, high surface brightness and excellent mechanical properties. It is especially suitable for sports materials. The directivity of shrinkage and contraction is small and the hardening speed is fast. Therefore, the holding time should be strictly controlled [4]. Because of the irregular structure and small thickness of the product, the accuracy requirement is above 6 levels, so it is difficult to classify and process. The material changes little along the thickness direction during the forming process, so no excess spills are produced in the die during the molding process, and only the geometry of the blank is changed.

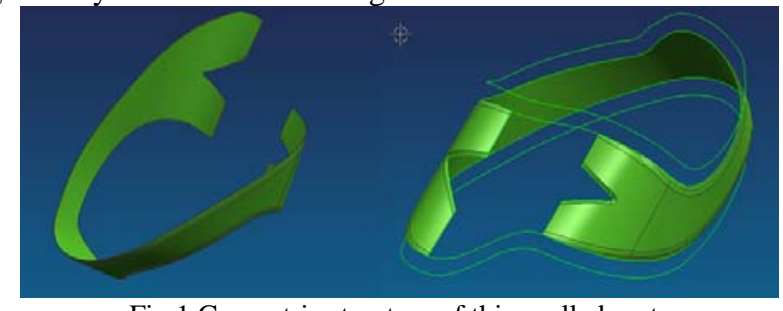

Fig.1 Geometric structure of thin-walled parts

\section{B. Molding characteristics}

The blanks of composite products have been made into corresponding shapes and geometric sizes before preheating. The function of the die is to change the shape of the blanks. In this process, the blanks of composite products do not produce excessive excess material and need to spill over, so the die structure cannot have spillover structure. The exterior quality of 
the product is good, the force is uniform and compact, and the amount of spills is less, which does not cause waste of raw materials. Therefore, this method is suitable for the forming of carbon fiber composite products [5]. Of course, this process also has some shortcomings, because the forming process needs heating, holding pressure, cooling and other processes, the production cycle is longer. In addition, the gap between the punch and the inner wall of the feeding chamber is small, so it is necessary to avoid damaging the matching part between the die and the core.

As mentioned above, there is almost no spill during the forming process, and the size of the die core and cavity directly determines the geometric boundary of the product. The die structure is divided into three parts: the upper die, the lower die and the middle core fixing plate. The parting surface of the die is parallel to the working table of the hydraulic press. The forming process of carbon fiber products needs five processes: preheating plastics, placing punch blocks, pressing, removing punch blocks and cooling. Firstly, the preheated polyacrylonitrile-based carbon fiber composites were manually placed in the cavity. Secondly, the middle core fixing plate is placed in the upper die through the guide mechanism. Finally, the pressure is pressed through the clamping of the guide mechanism.

\section{Structural Design OF Mould}

\section{A. Structure scheme}

The wall thickness of the product is only $2 \mathrm{~mm}$, and the thickness of the product should be uniform and the material should not be destroyed during the forming process. Therefore, the following factors must be taken into account. The mould is for thin-walled carbon fiber composite products. Because of its surface characteristics, when choosing the direction of pressure, it should avoid the uneven force on the products. Otherwise, the pressure at the parting line at the lower part of the plastic part is too high, which may lead to the phenomenon of overflow at the lower part of the plastic part or insufficient filling at the upper parting line.

After determining the direction of pressure, the position of the parting surface of the die keeps the product in the die after opening. According to the structural characteristics of the product, in order to make the forming pressure act uniformly on the blank and make the direction of the plastic part forming consistent with the direction of pressure, the cavity should be set in the lower die to facilitate the feeding and the flow of the plastic part. Pressure is pressurized to the inside of the wool through the combined core. Pressure can be effectively applied to composite products. The parts with high dimensional accuracy are not suitable for design in the direction of pressure application. Pressure direction design is based on the principle of pressure direction of carbon fiber product forming die, selection of parting surface and easy placement of core assemblies.

\section{B. Core Design Scheme}

Because the structure of the die is integral, if the core adopts the same structure form, the upside-down phenomenon will occur during assembly, and the open mould will be opened. Therefore, the core is segmented and the composite structure is adopted. This makes it easier to open the mould, as shown in Fig.2. The reverse taper ejector remolding method is simple to operate and cannot damage the moulded products. It is very helpful to improve the production efficiency.

Before the blank is loaded into the die, it needs to be preheated to make it soft, then put into the die for pressing, after heating and curing forming, then cooled, demoulding, etc., to the final forming. In the whole technological process, the product is most loaded in the process of holding pressure and easy to be destroyed. Therefore, it is very important to choose the proper clamping pressure to ensure the product's forming without damage. Therefore, the type of press is selected to provide basic parameters for product design.

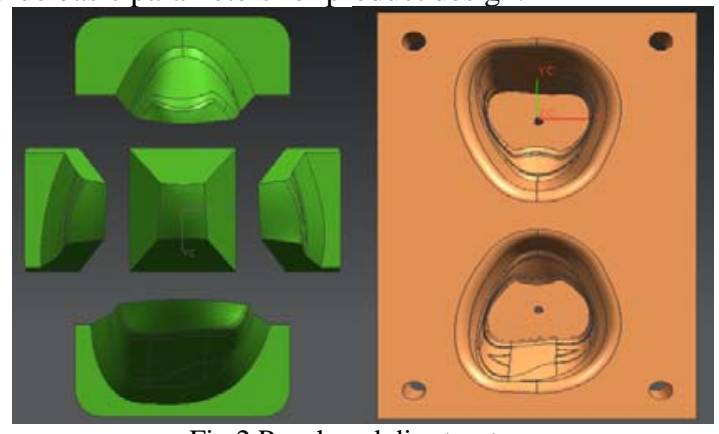

Fig.2 Punch and die structure

\section{Design of demoulding mechanism}

After completing the molding, the molded product is pushed out of the mould cavity by the demoulding mechanism [6]. When designing the mechanism, which demoulding structure should be adopted should be decided according to the structure shape of the product and the structure of the mould and other relevant factors. The usual demoulding methods include manual, maneuvering and pneumatic methods. Because of its light weight, small size and simple structure, this die is manually operated to push out the plastic parts. As shown in Figure 3, the product is removed from the die by operating the stripping structure of the side-band counter-tapered ejector rod.

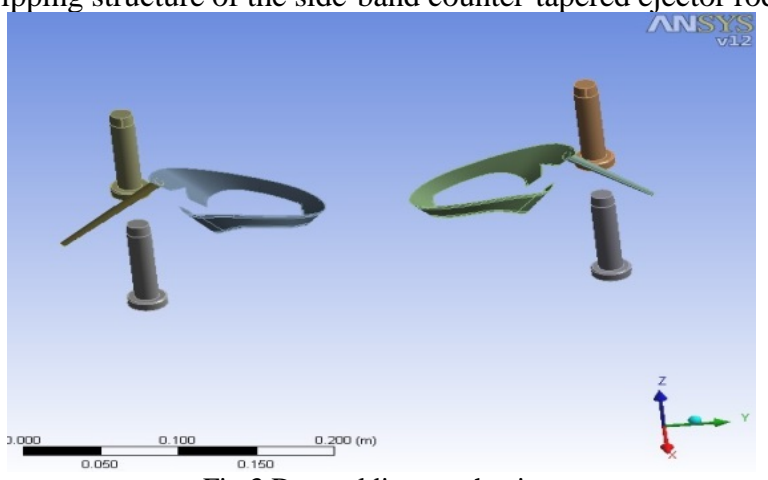

Fig.3 Demoulding mechanism

Whether the demoulding mechanism is reasonable or not has a great influence on the production efficiency and labor intensity of the mould, and plays a vital role in protecting the surface quality of composite products. The demoulding mechanism is compact and portable, with low labor intensity and high efficiency. To meet the purpose of die design, ensure that the product is left in the die after opening. Moreover, the hole on the side of the whole die has little effect on the strength of the die.

\section{Processing Technology Requirements of Die Core}

One of the advantages of using the method of moulding is that the moulding process can make the moulding precision of the products higher [7]. Core and cavity are the main forming parts of the die. The surface finish and geometric dimension accuracy of the core and cavity directly determine the forming effect of the composite products. Because the surface of the die requires high precision and good forming quality, in order to provide the processing quality of the die, it is necessary to 
compile reasonable processing rules and realize it by means of numerical control equipment.

The core is made up of five parts, as shown in Fig.4, each part is processed separately. This method is relatively easy to process as a whole, and it also solves the problem of upsidedown of the core. Die assembly is a process that can be carried out only when the processing of each component meets the requirements of design accuracy. Because there are certain size errors in processing individual parts of the die, it is easy to cause the accumulation and superposition of size errors in die assembly, resulting in low assembly accuracy, or even the phenomenon of unable to assemble. Therefore, only by strictly controlling the manufacturing process of the die, can the precision of the die be guaranteed. In addition, die assembly must coordinate the relationship between various parts, not scratch in the main forming parts of the die, strictly in accordance with the order of assembly process, until the die assembly is qualified.

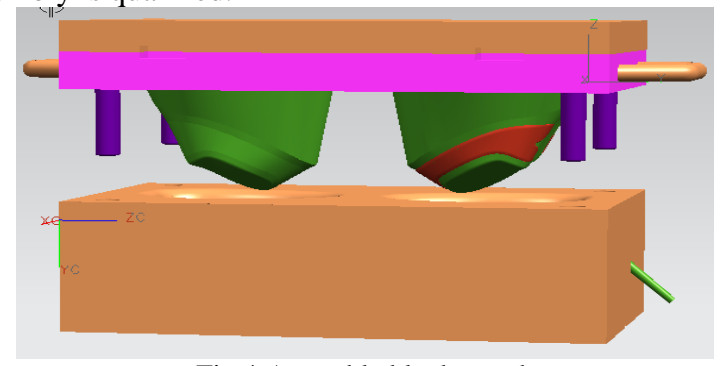

Fig.4 Assemble block punch

\section{E. Main parts of mould}

The forming mould is formed on YB32-63 four-column universal hydraulic press. The parting surface is parallel to the working table of the press, and is divided into three parts: the upper mould, the lower mould and the middle core fixing plate. When forming, the pre-heated polyacrylonitrile-based carbon fiber blank with a certain thickness cut according to the forming size of the cavity is first placed manually on the inner surface of the cavity after preheating, and then the middle core fixing plate is placed on the upper mould through the guide mechanism. Then put the core in the middle core fixing plate in turn, pay attention to putting the core in the middle at last, otherwise there will be upside-down in the core cannot be put in, through the guide mechanism, installed in the upper template. Pressure is applied by the hydraulic press, and then the curing process is heated and solidified.

After forming, the mould is cooled and removed from the worktable of the hydraulic press. Manual demoulding is adopted. In operation, the pry bar is inserted into the groove between the upper template and the middle core fixing plate to make the guide pillar come out of the guide sleeve. Then, the M8 screw is used to screw into the screw hole of the middle core, and the middle core is taken out. Then the middle core fixing plate and the groove of the lower mould are used to separate the guide sleeve through the guide pillar. At this time, other core can be fixed through the middle core to the side of the guide plate. The handle of the face is taken out together, and the plastic part is finally taken out through the reverse taper ejector rod. In this way, the opening steps are designed to avoid the friction damage between the core and the cavity when opening and closing the mould, so that the plastic parts are deformed.

Since there is no spill in the forming process of the composite products, the feeding cavity of the mould and the mould cavity are combined into one. The forming pressure will be applied to the products. The precision of the punch and the concave mould of the non-overflow carbon fiber product forming mould are higher, so after the product forming, there will be no excessive flying edge. And a small amount of flying edge direction is consistent with the normal direction of the product or has a certain angle with the surface of the product, so it is easier to clean up.

\section{CONCLUSION}

When designing the forming die for carbon fiber products, the size of the feeding chamber should be designed according to the geometry, material type and feeding mode of the products. Because the thickness of the product does not change significantly and the surface of the product does not extend, the die cavity size is approximately equal to that of the composite product. Generally, a feeding cavity is needed on the cavity of a forming die. The volume of the feeding cavity should be equal to the volume of the plastic material minus the volume of the cavity. However, because the shrinkage of carbon fibers is very small, it is not necessary to set up a feeding chamber.

\section{REFERENCES}

[1] A.L. LU. "Research on gypsum reinforcement technology for ceramic moulds," China Mechanical Engineering, vol.12, pp.183-186, October 2011.

[2] J.C. GU. "Machining technology of hardened steel mould for automotive large cover parts," Hot Material Report, vol.2, pp. 143-146, August 2015.

[3] Y. LI. "Research on key technology of die surface modification for flexible three-dimensional stretchbending forming," China Mechanical Engineering, vol.26,pp. 1611-1615, January 2016.

[4] W. CHENG, Q.H. LIAO. "Application of 3d printing technology in mold manufacturing," Light Industry Machinery, vol.33, pp. 107-110, February 2015.

[5] Y.M. FU. "Key technologies and research progress of cooling system for injection moulds,” Journal of Yanshan University, vol.31, pp.95-102, May 2017.

[6] X.L. WANG. "Application of digital technology in design and manufacture of stamping dies," Science and Technology Perspective, vol.22, pp. 268-268, June 2014.

[7] X.W. LIU. "Structural design and strength analysis of pseudo-shunt extrusion die for cantilever aluminium alloy profiles," Journal of Rock Mechanics and Engineering, vol.33, pp. 1432-144, May 2014. 